\title{
Article \\ Cytological Diagnosis of Pancreatic Solid-Pseudopapillary Neoplasm: A Single-Institution Community Practice Experience
}

\author{
Brant G. Wang * ${ }^{\mathbb{D}}$, Haresh Mani, Zoe Q. Wang and Wenping Li
}

check for updates

Citation: Wang, B.G.; Mani, H.; Wang, Z.Q.; Li, W. Cytological Diagnosis of Pancreatic Solid-Pseudopapillary Neoplasm: A Single-Institution Community Practice Experience. Diagnostics 2022, 12, 449. https://doi.org/10.3390/ diagnostics12020449

Academic Editors: José

A. Jiménez-Heffernan and

Cristina Díaz del Arco

Received: 1 January 2022

Accepted: 29 January 2022

Published: 9 February 2022

Publisher's Note: MDPI stays neutral with regard to jurisdictional claims in published maps and institutional affiliations.

Copyright: (c) 2022 by the authors. Licensee MDPI, Basel, Switzerland. This article is an open access article distributed under the terms and conditions of the Creative Commons Attribution (CC BY) license (https:// creativecommons.org/licenses/by/ $4.0 /)$.
Department of Pathology, Inova Fairfax Hospital, 3300 Gallows Road, Falls Church, VA 22042, USA; haresh.mani@inova.org (H.M.); zwang122@alumni.jh.edu (Z.Q.W.); wenping.li@inova.org (W.L.)

* Correspondence: brant.wang@inova.org; Tel.: +1-703-776-4913; Fax: +1-703-776-3100

Abstract: Introduction. Pancreatic solid-pseudopapillary neoplasm (SPN) is a rare tumor that typically occurs in young females. Although a cytological diagnosis may be easily made in this age group when there are typical features, atypical clinical presentations and unusual cytological features may make this a challenging diagnosis. We present our single-institution experience in a cohort of these tumors, outlining both typical and atypical features. Awareness of unusual clinical and cytological features can help to avoid pitfalls during diagnosis. Methods. We performed a review of all cases of pancreatic SPNs diagnosed over a 15-year period (January 2007 to December 2021). Detailed cytological, clinical, and follow-up histological features were presented and analyzed. Results. Twenty-two cases of SPN were diagnosed at our institution during this 15 -year period. Patients ranged from 12 to 73 years of age (mean 33 y, median 26 y) and included 19 females and 3 males. Seventeen patients had cytological material, and fourteen were diagnosed by EUS-FNA. Typical cytological features included papillary clusters with central capillaries, myxoid stroma, monomorphism, cercariform cells, and hyaline globules. Atypical or unusual cytological features that were seen in a few cases were multinucleated giant cells, clear cells, and/or foamy macrophages. A few cases showed features that were similar to pancreatic neuroendocrine tumors (PanNETs). Tumor cells were always positive for $\beta$-catenin, CD10, CD56, cyclin-D1, progesterone receptor (PR), and vimentin by immunohistochemistry. They were always negative for chromogranin. Pancytokeratin and synaptophysin stains were positive in $9 \%$ and $46 \%$ of cases evaluated, respectively. All cases had histological confirmation on resection. The median follow-up duration was 69 months (a range of 2-177 months), with only three cases lost to follow-up. No recurrence or metastasis was identified. Conclusions. We present our experience with cytological diagnoses of SPN in a well-characterized cohort of 22 patients with histological correlation and follow-up data. These tumors occur over a wide range and show varied cytological features. SPNs can be confidently diagnosed on limited cytological material, with limited panel immunohistochemistry aiding diagnosis in atypical cases. Recognizing the associated degenerative changes is crucial in avoiding a misdiagnosis.

Keywords: solid-pseudopapillary neoplasm; pancreas; cytology; immunohistochemistry

\section{Introduction}

Solid-pseudopapillary neoplasm (SPN) of the pancreas is a rare tumor usually seen in young female patients. It is a neoplasm with a low malignant potential, and patients tend to have a good prognosis, especially compared to other malignant pancreatic neoplasms [1-6]. A definitive diagnosis is therefore crucial for correct patient management.

The clinical and radiological features of SPNs mimic those of other pancreatic neoplasms. They typically present as solid and cystic masses anywhere along the pancreas [1-6]. A preoperative diagnosis can be made on cytology specimens if one keeps this differential in mind. Therefore, cytology is an important tool in the diagnosis and management triage [7-15]. We summarize our experience in the cytodiagnosis of SPN, with an emphasis 
on cytological clues and a simplified panel for confirmatory immunohistochemistry. A few diagnostic pitfalls are also discussed.

\section{Materials and Methods}

We searched files in our Department of Pathology for a diagnosis of SPN over a 15year period between January 2007 and December 2021. We included both cytology and surgical pathology data in our search. All available material was reviewed. These included Diff-Quik-stained direct smears, Papanicolaou-stained direct smears or ThinPrep prepared slides, hematoxylin and eosin (H\&E)-stained cell block sections, and immunohistochemical stains. Emphasis was placed on detailing individual previously defined cytological features including cellularity, pseudopapillary configuration, single cells with a cytoplasmic tail ("cercariform" cells), nuclear grooves/folding, nucleoli, cytoplasmic vacuoles, and intracytoplasmic eosinophilic hyaline globules. Any other findings were also documented. The findings of pertinent immunohistochemistry results were summarized. Follow-up histological resections were reviewed for the correctness of cytological diagnoses, and clinical follow-up information was obtained.

\section{Results}

There were a total of 22 cases of SPN in our files over this 15-year period, including 19 females and 3 males. Patients ranged in age from 12 to 73 years (mean 33, median 26). However, the three males were aged 23 years, 25 years, and 26 years. Patients had presented with abdominal pain or discomfort. One patient (Case \#21) had a sports-related trauma, and the tumor was incidentally discovered. The tumors were presented at the pancreatic tail in 12 cases $(54.5 \%)$, body in 9 cases (41\%), and head in 1 case (4.5\%). Most tumors (18, $82 \%)$ were described as solid and cystic on imaging and gross examination, with three (13.5\%) tumors being purely solid, and one (4.5\%) being cystic. Tumor sizes ranged from 1.2 to $15 \mathrm{~cm}$. There was no significant association between size and age, gender, or tumor site. Clinical and radiological information, as well as gross examination, is summarized in Table 1.

Table 1. SPN: clinical presentation, radiological/gross features, and cytological correlation.

\begin{tabular}{llllllll}
\hline Case & $\begin{array}{l}\text { Age } \\
\text { (Years) }\end{array}$ & Sex & Site & $\begin{array}{l}\text { Radiology/Gross } \\
\text { Features }\end{array}$ & $\begin{array}{l}\text { Size } \\
\text { (cm) }\end{array}$ & ROSE Diagnosis & $\begin{array}{l}\text { FNA/Biopsy } \\
\text { Diagnosis }\end{array}$ \\
\hline 1 & 65 & F & Body & Solid and cystic & 4.0 & $\begin{array}{l}\text { Atypical cells with mucinous } \\
\text { features }\end{array}$ & SPN \\
2 & 39 & F & Tail & Cystic & 3.0 & Serous papillary lesion & SPN \\
3 & 28 & F & Body & Solid and cystic & 4.0 & NA & SPN \\
4 & 26 & F & Tail & Solid and cystic & 4.0 & NA & SPN \\
5 & 33 & F & Body & Solid and cystic & 6.5 & Lesional tissue & SPN \\
6 & 26 & F & Tail & Solid and cystic & 1.5 & Suspicious for SPN vs. PanNET & SPN \\
7 & 24 & F & Tail & Solid and cystic & 4.0 & SPN & SPN \\
8 & 26 & M & Tail & Solid and cystic & 3.5 & NA & SPN \\
9 & 25 & M & Body & Solid & 2.2 & Favor PanNET & SPN \\
10 & 29 & F & Body & Solid & 2.9 & Lesional tissue & SPN \\
11 & 23 & M & Body & Solid and cystic & 4.8 & NA & SPN \\
12 & 41 & F & Tail & Solid and cystic & 2.2 & NA & SPN \\
13 & 20 & F & Head & Solid & 6.0 & NA & SPN \\
14 & 73 & F & Body & Solid and cystic & 1.2 & NA & SPN \\
15 & 21 & F & Tail & Solid and cystic & 15 & Round cells & SPN (biopsy) \\
16 & 21 & F & Tail & Solid and cystic & 12 & Lesional cells & SPN (biopsy) \\
17 & 47 & F & Body & Solid and cystic & 4.7 & Tumor & SPN (biopsy) \\
18 & 46 & F & Tail & Solid and cystic & 4.5 & NA & NA \\
19 & 14 & F & Tail & Solid and cystic & 3.7 & NA & NA \\
20 & 71 & F & Body & Solid and cystic & 15 & NA & NA \\
21 & 12 & F & Tail & Solid and cystic & 3.5 & NA & NA \\
22 & 16 & F & Tail & Solid and cystic & 3.5 & NA & NA \\
\hline
\end{tabular}

Abbreviations: ROSE, rapid on-site evaluation; NA, not available; SPN, solid-pseudopapillary neoplasm; PanNET, pancreatic neuroendocrine tumor; FNA, fine needle aspiration. 
Of the 22 cases, 5 only had surgical pathology material without a prior cytological diagnosis and were therefore excluded from further analysis. All of the remaining 17 cases were confirmed to be SPN on resection. Based on our institution's practice, all cases had Diff-Quik-stained smears. Papanicolaou-stained direct smears or ThinPrep material were available for review in two cases. A detailed review of the cytological features was undertaken (summarized in Table 2). All but one showed high cellularity. All 17 cases showed branching papillary-like cellular clusters (Figure 1A,B). All but one case showed central capillaries within the papillary clusters (Figure 1A,B). Similarly, all but one case showed myxoid fibrovascular stromal fragments (Figure 1D-F), and all but one showed numerous loosely cohesive or single monomorphic neoplastic cells (Figure 1C). These monomorphic cells had a plasmacytoid morphology. Tumor cells showed fine nuclear chromatin and nuclear grooves (better seen on Papanicolaou and H\&E stains) (Figures 1B,F,H and 2C,E). Binucleation was noted in all cases. Cercariform cells were seen on all smears with high cellularity, but not on touch imprint material (Figures $1 \mathrm{~B}$ and $2 \mathrm{~F}$ ). Neither necrosis nor mitosis was seen in any of the cases. The above features were therefore considered to be usual or typical features since they were seen in almost all cases.

A few cases showed unusual or atypical features. Background foamy macrophages (Figure 1C,D) and/or cholesterol crystals (Figure 2A) were seen in 10 cases and 1 case, re-spectively. These were considered to be degenerative changes that often accompany cell discohesion and breakdown in pseudopapillary tumors. One case showed a prominent clear cell change (Figure 2B,C), raising a differential diagnosis of metastatic renal cell carcinoma, or PanNET with clear cell changes. Large atypical multinucleated giant cells were seen in two cases with cytological material (Figure 2D-H). Giant cell nuclei varied from being vesicular with prominent nucleoli to hyperchromatic (Figure 2E,H).

Table 2. Cytomorphology of $17 \mathrm{SPNs}$ of the pancreas on FNA smears/touch prints and cell block/biopsy.

\begin{tabular}{|c|c|c|c|c|c|c|c|}
\hline Case & Papillation & $\begin{array}{l}\text { Monomorphic } \\
\text { Cells }\end{array}$ & $\begin{array}{l}\text { Central } \\
\text { Capillaries }\end{array}$ & $\begin{array}{l}\text { Nuclear } \\
\text { Groove }\end{array}$ & $\begin{array}{l}\text { Myxoid } \\
\text { Fibrovascular } \\
\text { Stroma }\end{array}$ & $\begin{array}{l}\text { Cytoplasmic } \\
\text { Hyaline } \\
\text { Globules }\end{array}$ & $\begin{array}{l}\text { Atypical } \\
\text { Multinucleated } \\
\text { Cells }\end{array}$ \\
\hline 1 & + & + & + & + & + & + & - \\
\hline 2 & + & + & + & + & + & + & - \\
\hline 3 & + & + & + & + & + & + & - \\
\hline 4 & + & + & + & + & + & + & - \\
\hline 5 & + & + & + & + & + & + & - \\
\hline 6 & + & + & + & + & + & + & - \\
\hline 7 & + & + & + & + & + & + & - \\
\hline 8 & + & + & + & + & - & + & - \\
\hline 9 & + & + & + & + & + & + & - \\
\hline 10 & + & + & + & + & + & + & - \\
\hline 11 & + & + & + & + & + & + & - \\
\hline 12 & + & + & + & + & + & + & + \\
\hline 13 & + & + & + & + & + & + & - \\
\hline 14 & + & - & - & + & + & + & + \\
\hline 15 & + & + & + & + & + & + & - \\
\hline 16 & + & + & + & + & + & + & - \\
\hline 17 & + & + & + & + & + & + & - \\
\hline
\end{tabular}




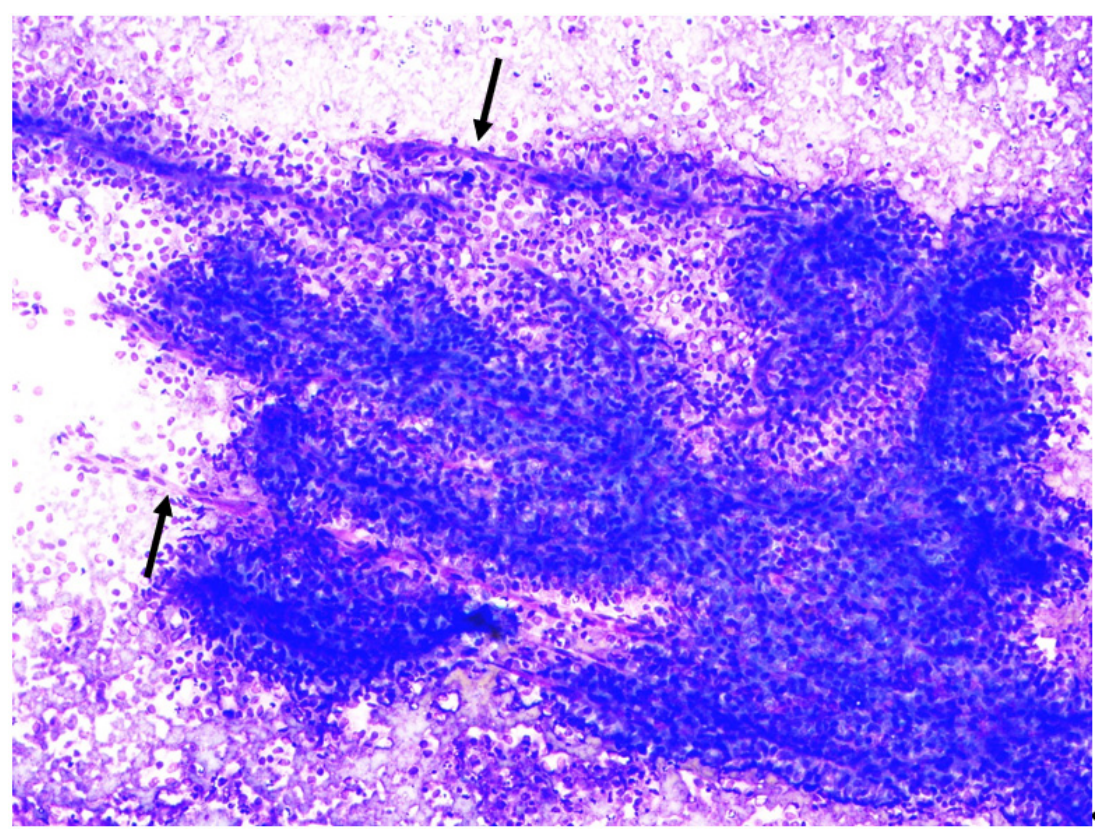

(A)

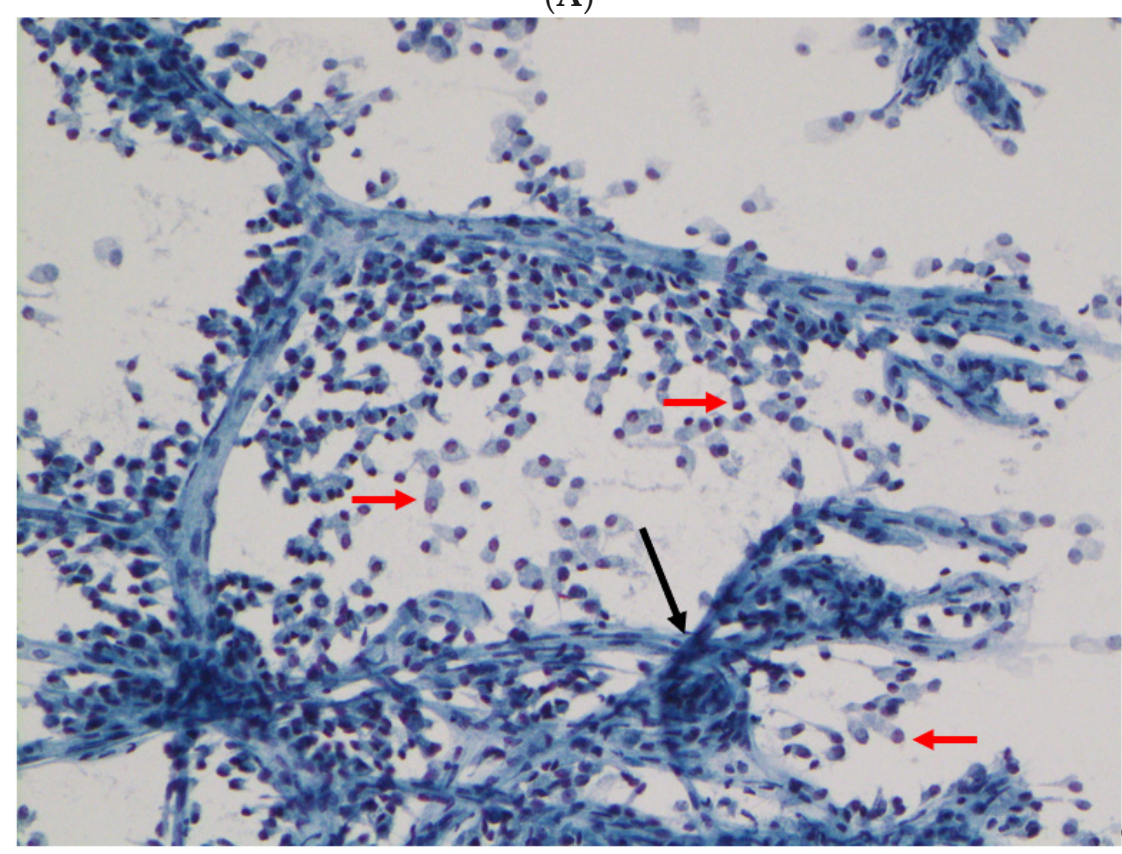

(B)

Figure 1. Cont. 


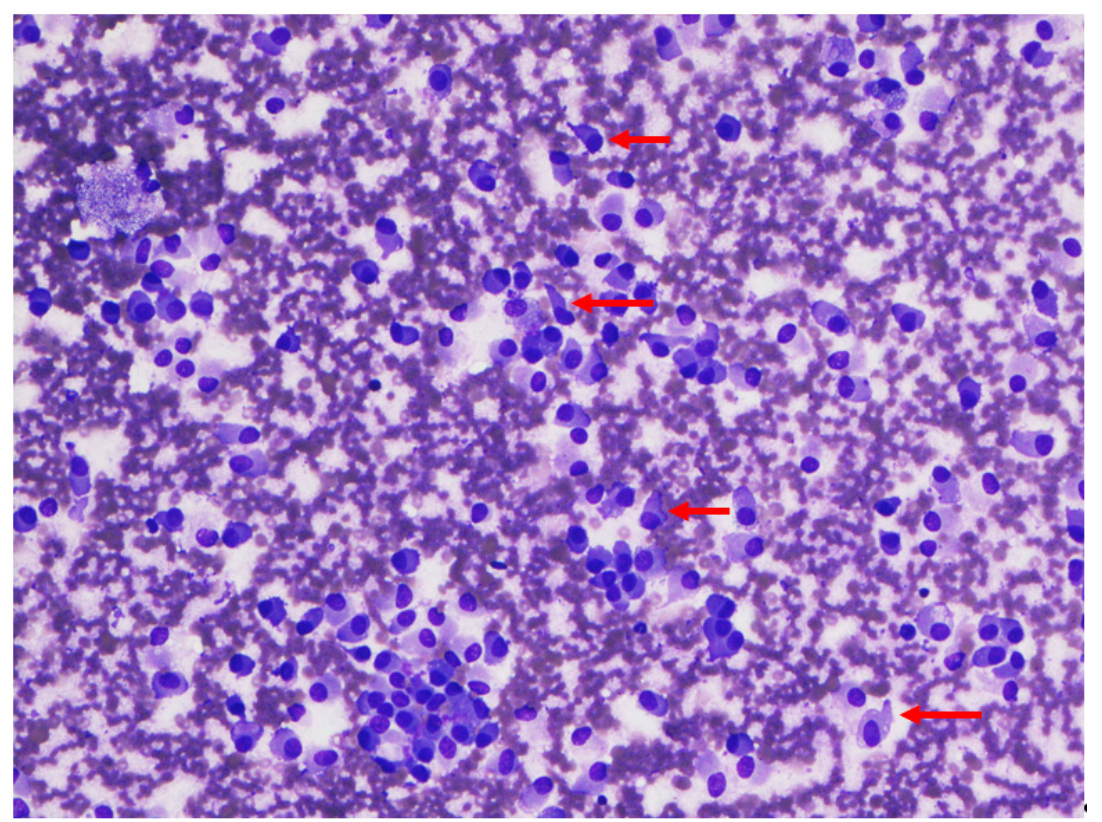

(C)

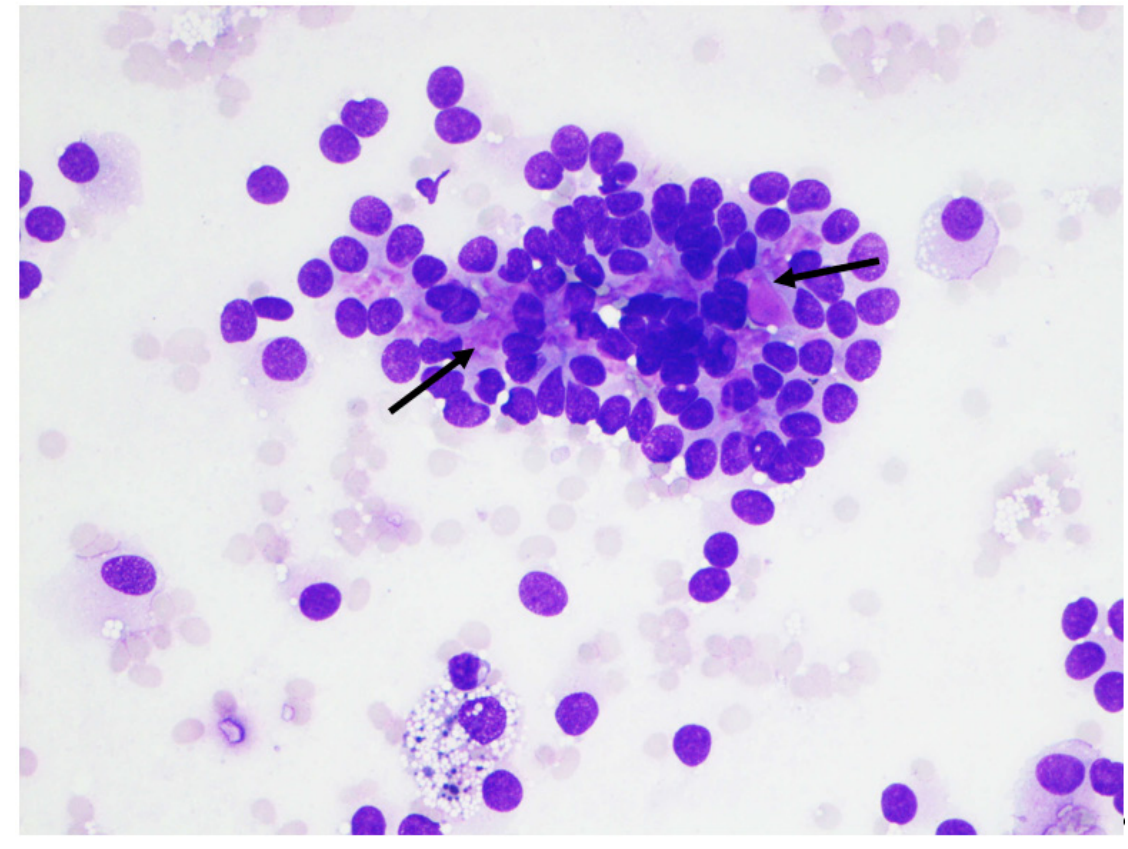

(D)

Figure 1. Cont. 


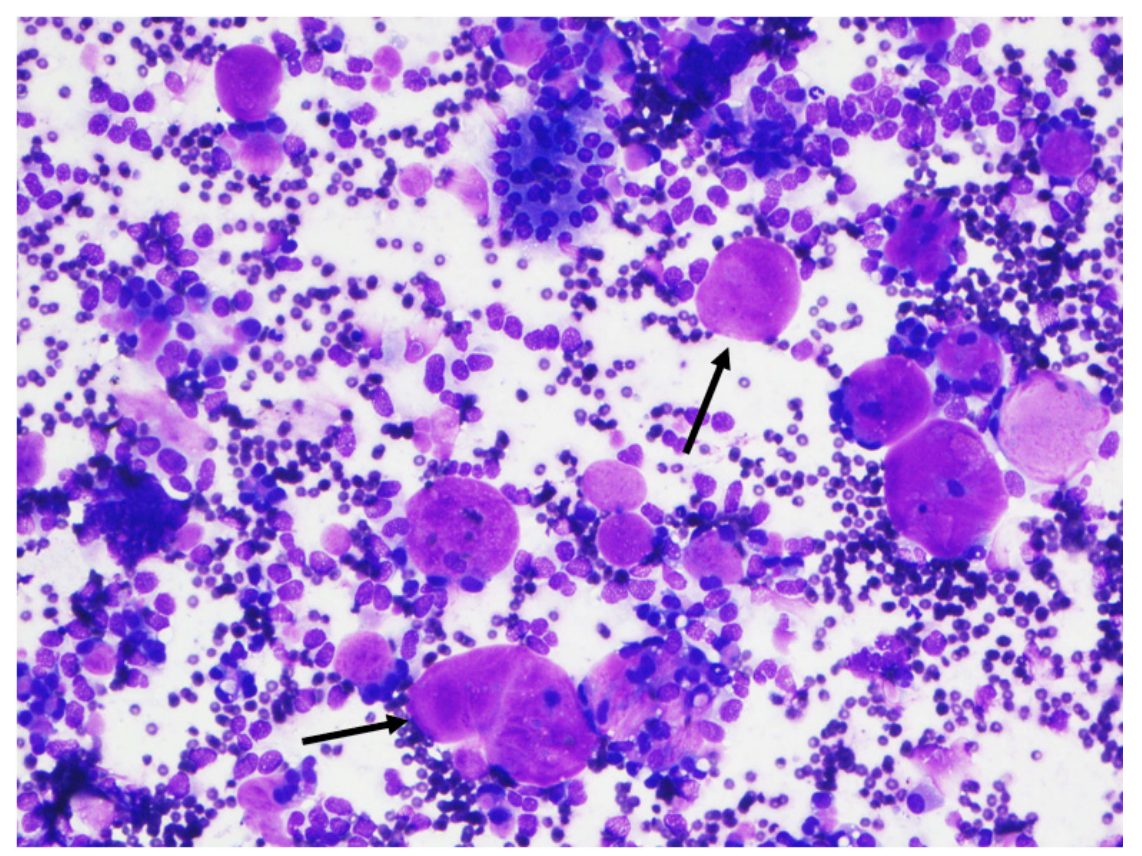

(E)

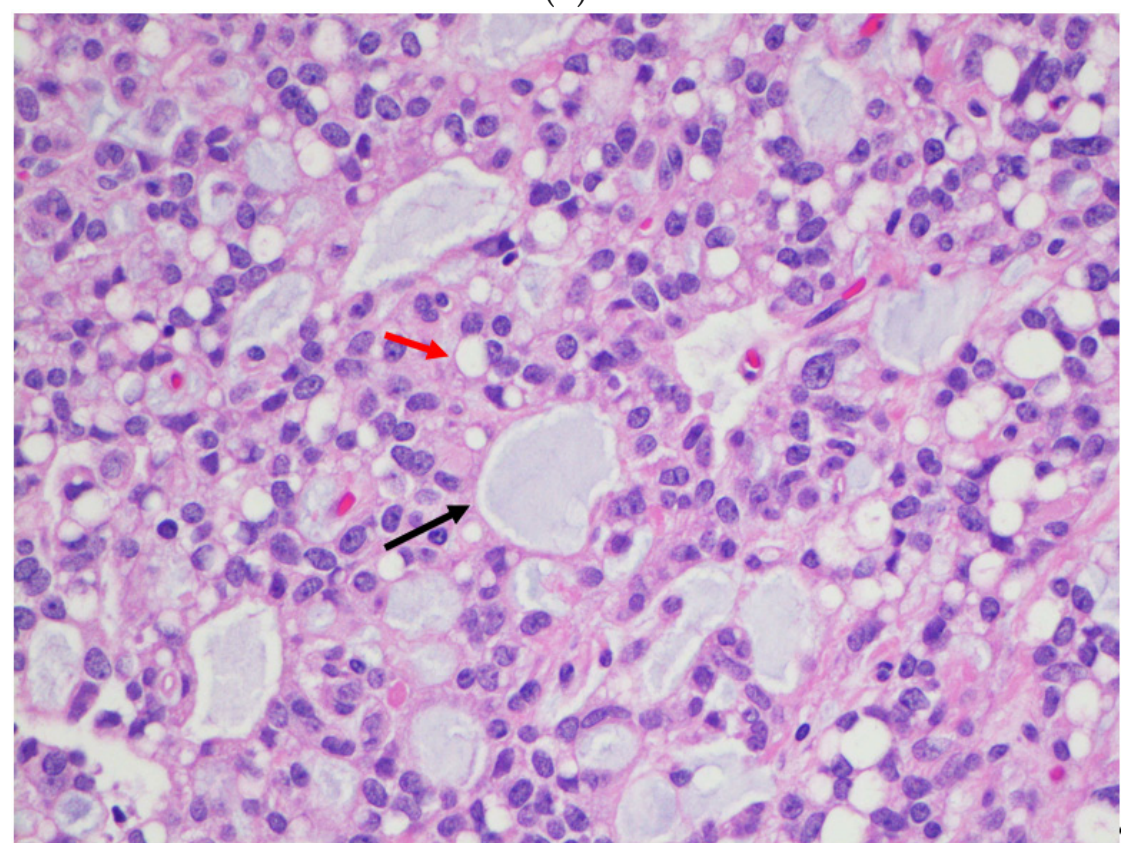

(F)

Figure 1. Cont. 


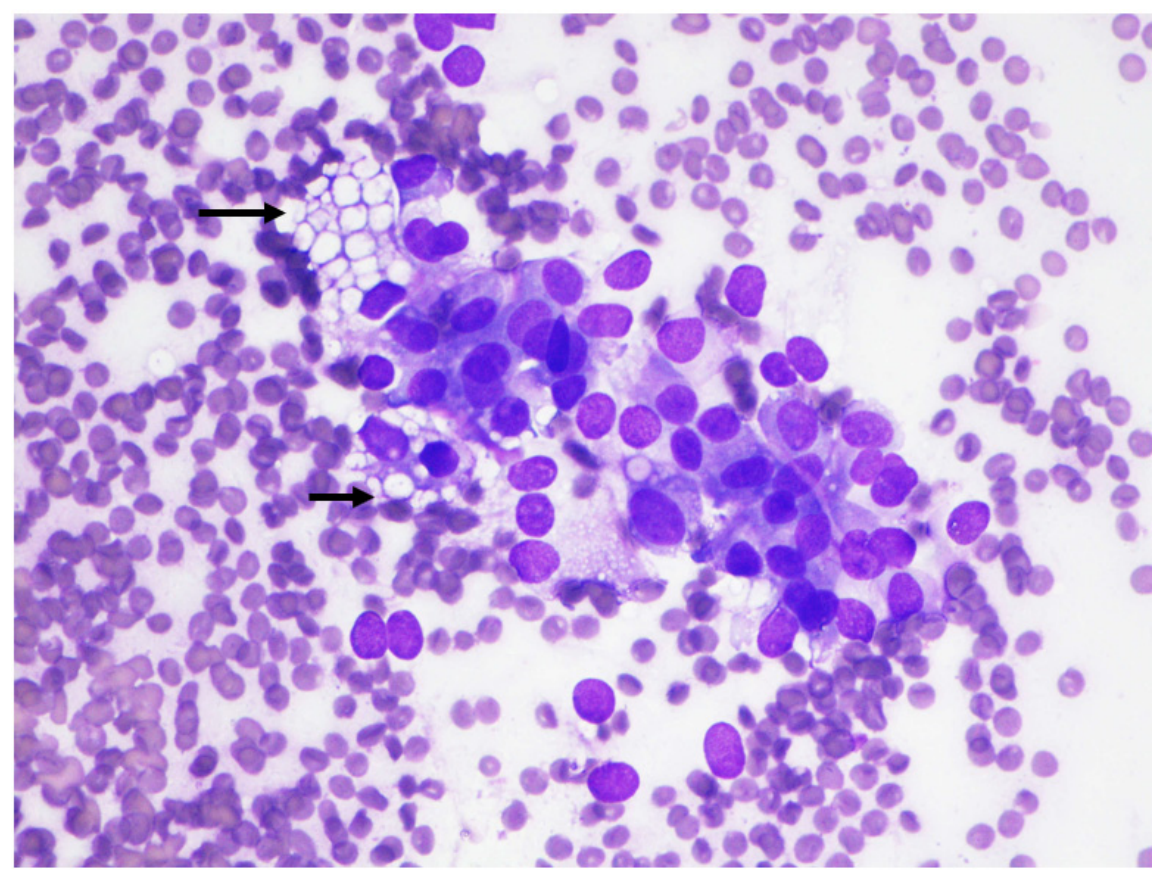

(G)

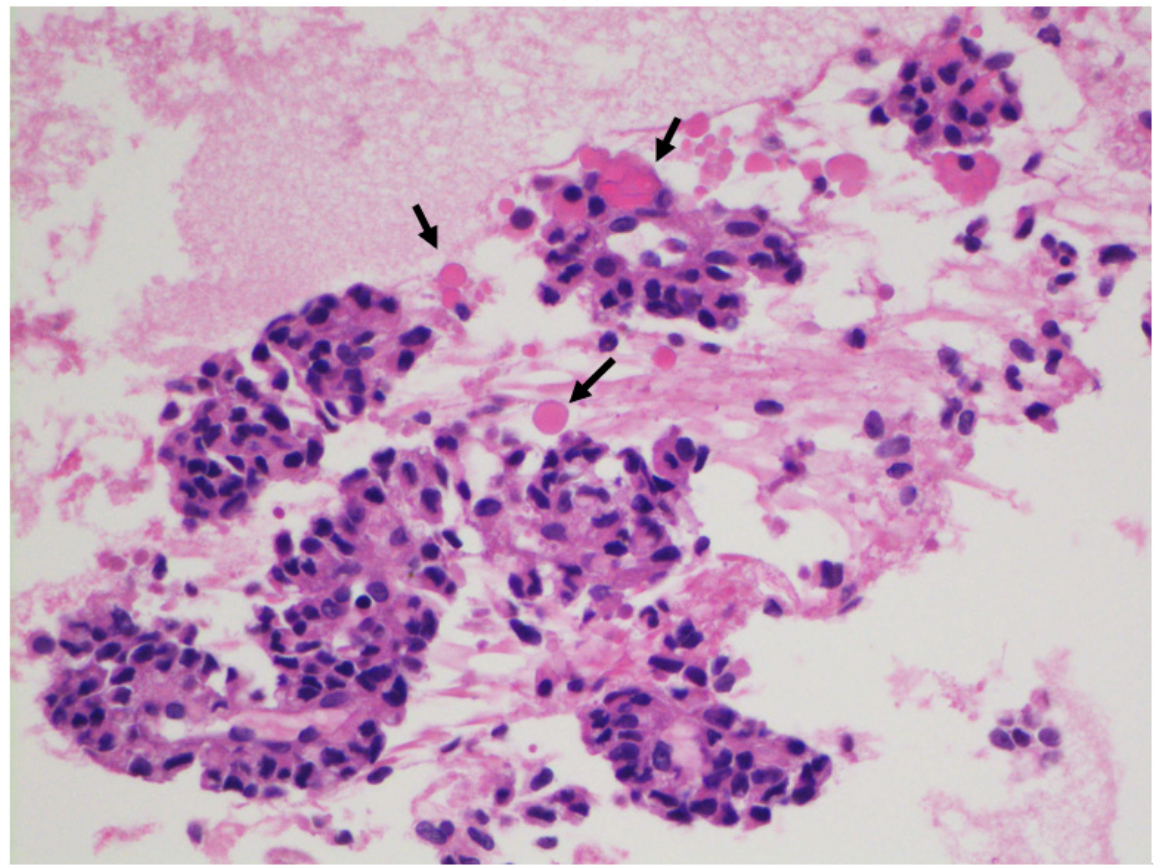

(H)

Figure 1. (A) Cellular aspirate with branching pseudopapillary fragments in a straight line, L shape, and $\mathrm{C}$ shape; central delicate capillaries (black arrows) surrounded by discohesive small- to mediumsized monomorphic neoplastic cells (Case \#7, EUS-FNA, Diff-Quik, original magnification $\times 100$ ). (B) Delicate central capillary network (black arrow) and discohesive cercariform cells (red arrows) (Case \#3, Papanicolaou, EUS-FNA, original magnification $\times 200$ ). (C) Relatively uniform plasmacytoid single neoplastic cells, with some showing a cytoplasmic tail (red arrows) ("cercariform cell") (Case \#3, EUS-FNA, Diff-Quik, original magnification $\times 200$ ). (D) Monomorphic neoplastic cells with extracellular metachromatic magenta material (black arrows). Note the foamy macrophage in the lower field (Case \#3, EUS-FNA, Diff-Quik, original magnification $\times 400$ ). (E) An extreme example of prominent extracellular metachromatic magenta material (black arrows), corresponding to the myxoid stroma seen in $($ F) (Case \#6, EUS-FNA, Diff-Quik, original magnification $\times 200)$. (F) Solid-pseudopapillary 
neoplasm with prominent myxoid fibrovascular stroma (black arrow) and paranuclear vacuoles (red arrow) (Case \#6, resection, H\&E, original magnification $\times 400)$. (G) Neoplastic cells with intracytoplasmic vacuoles (black arrows) on ROSE, interpreted as "atypical cells with mucinous features", corresponding to the intracytoplasmic eosinophilic hyaline globules seen on the H\&E stain in $(\mathbf{H})$ (Case \#1, EUS-FNA, Diff-Quik, original magnification $\times 400)$. (H) Neoplastic cells with intracytoplasmic eosinophilic hyaline globules (black arrows) (Case \#1, EUS-FNA, cell block, H\&E, original magnification $\times 200)$.

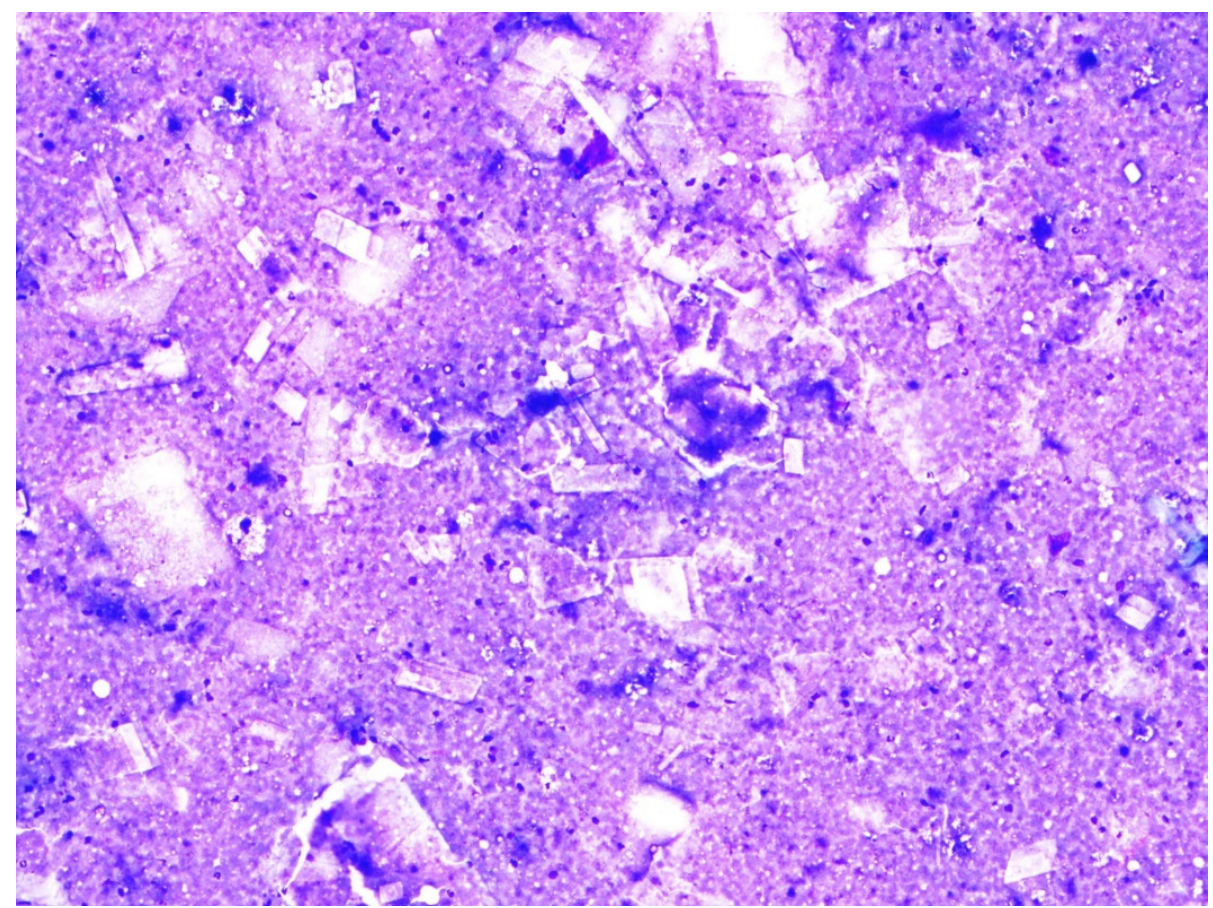

(A)

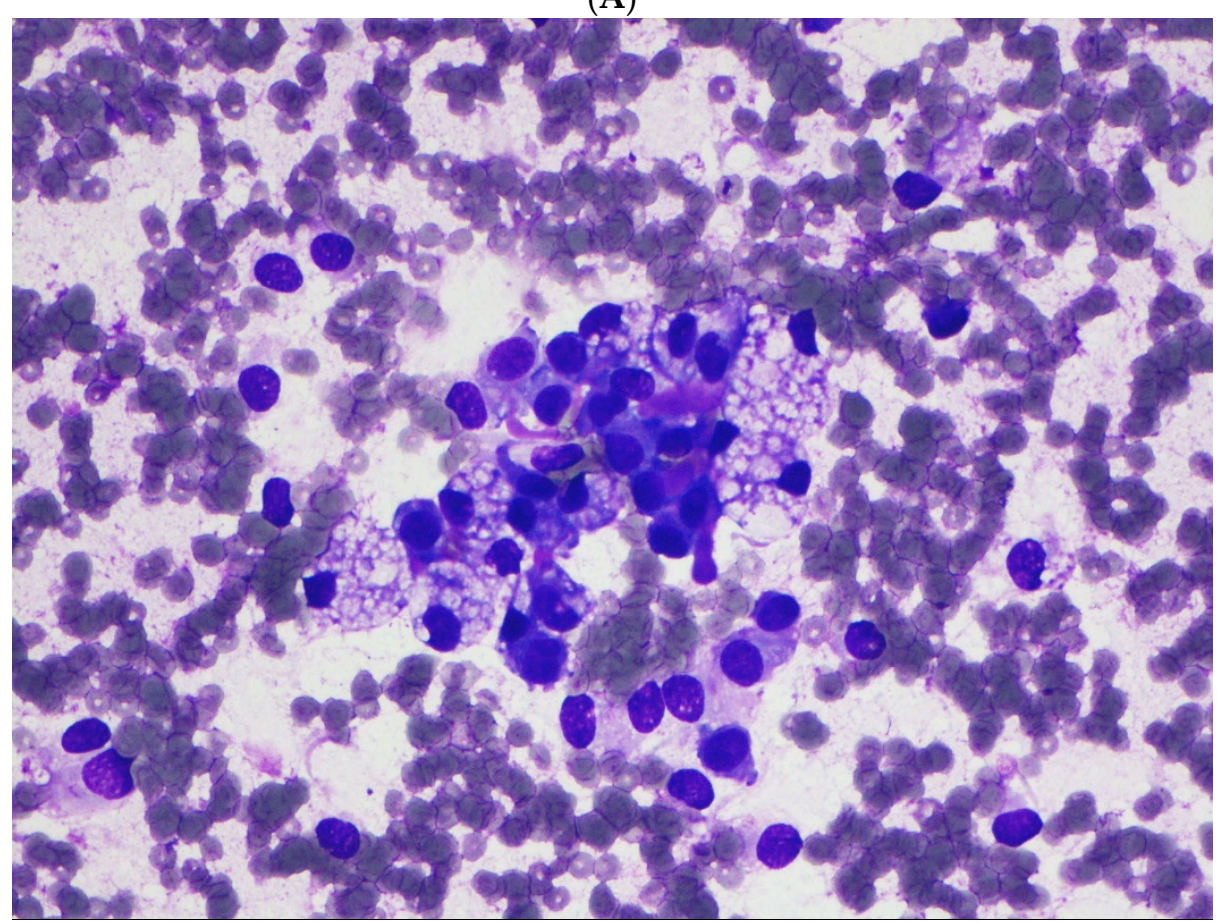

(B)

Figure 2. Cont. 


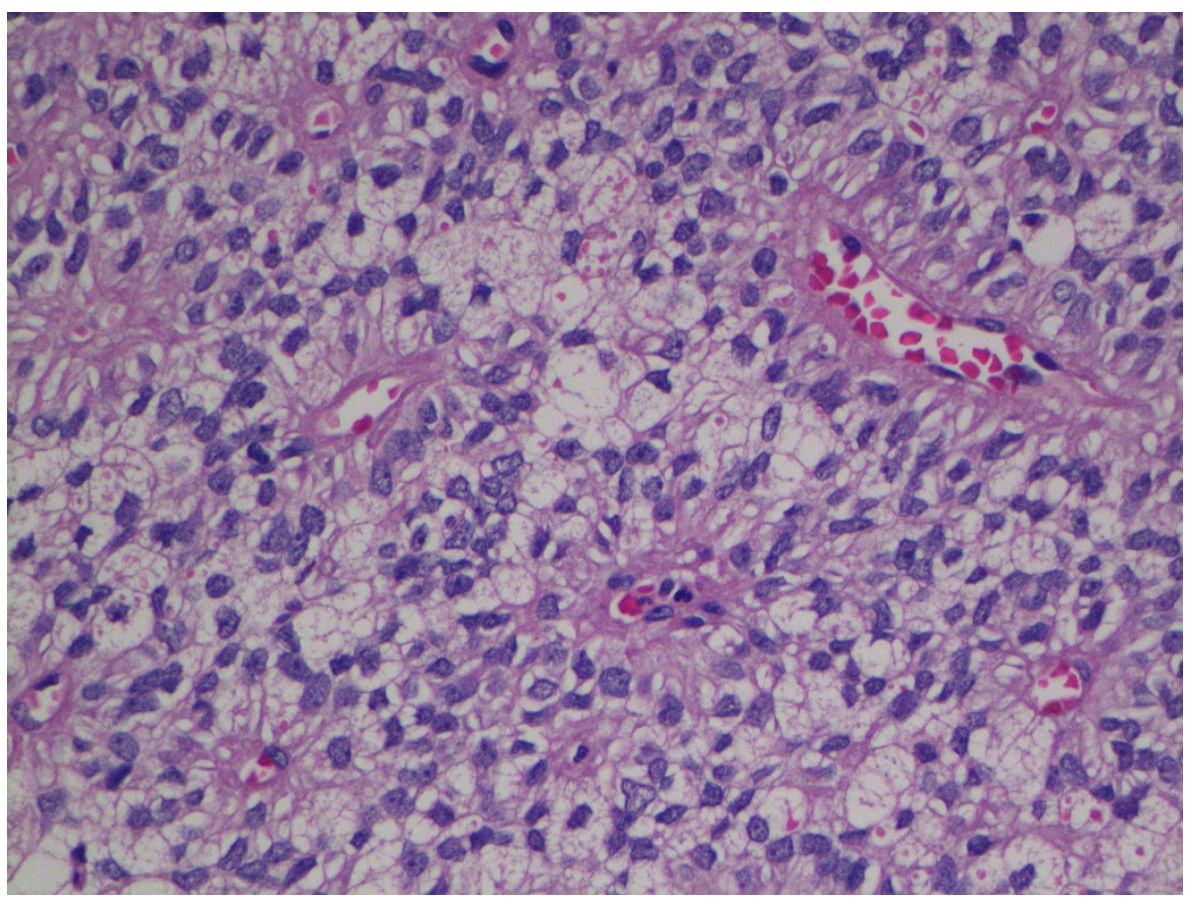

(C)

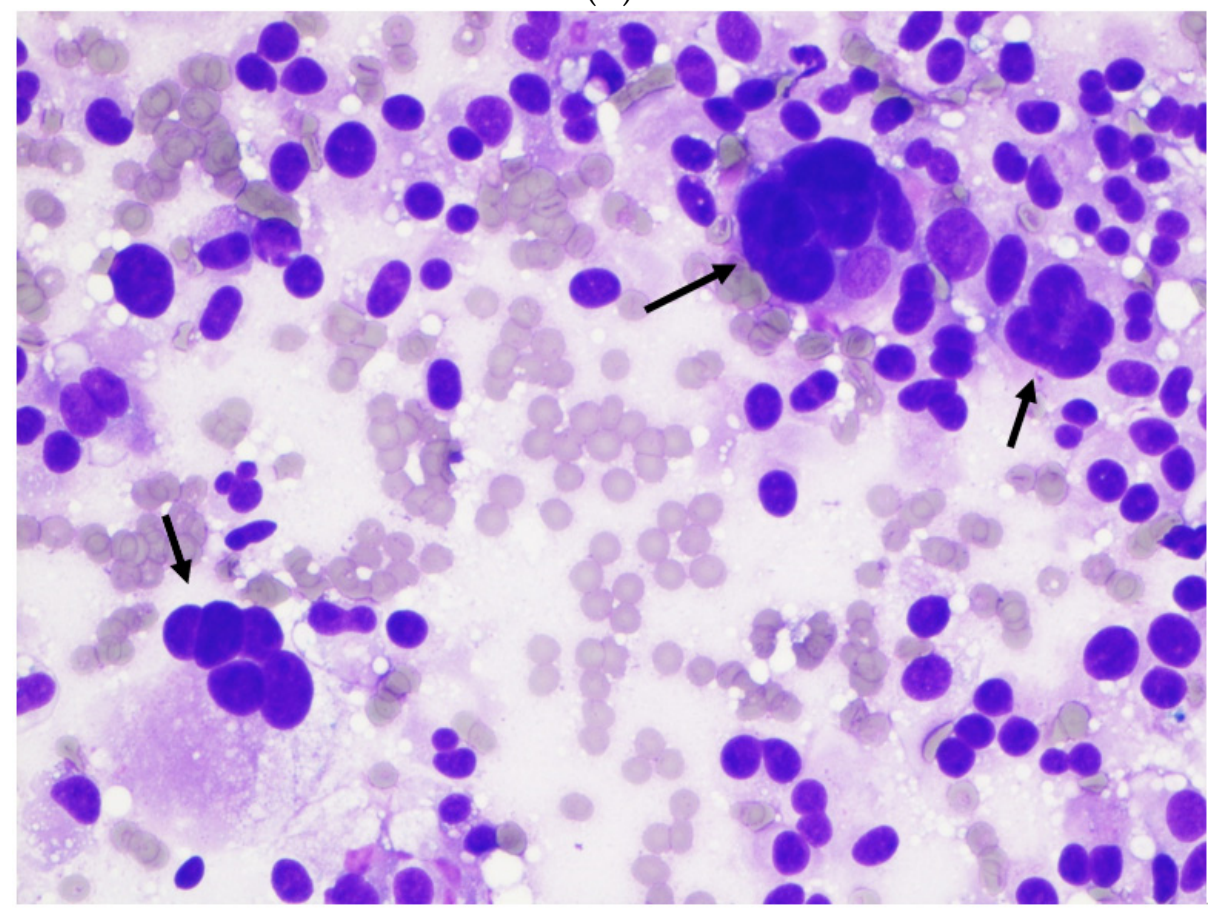

(D)

Figure 2. Cont. 


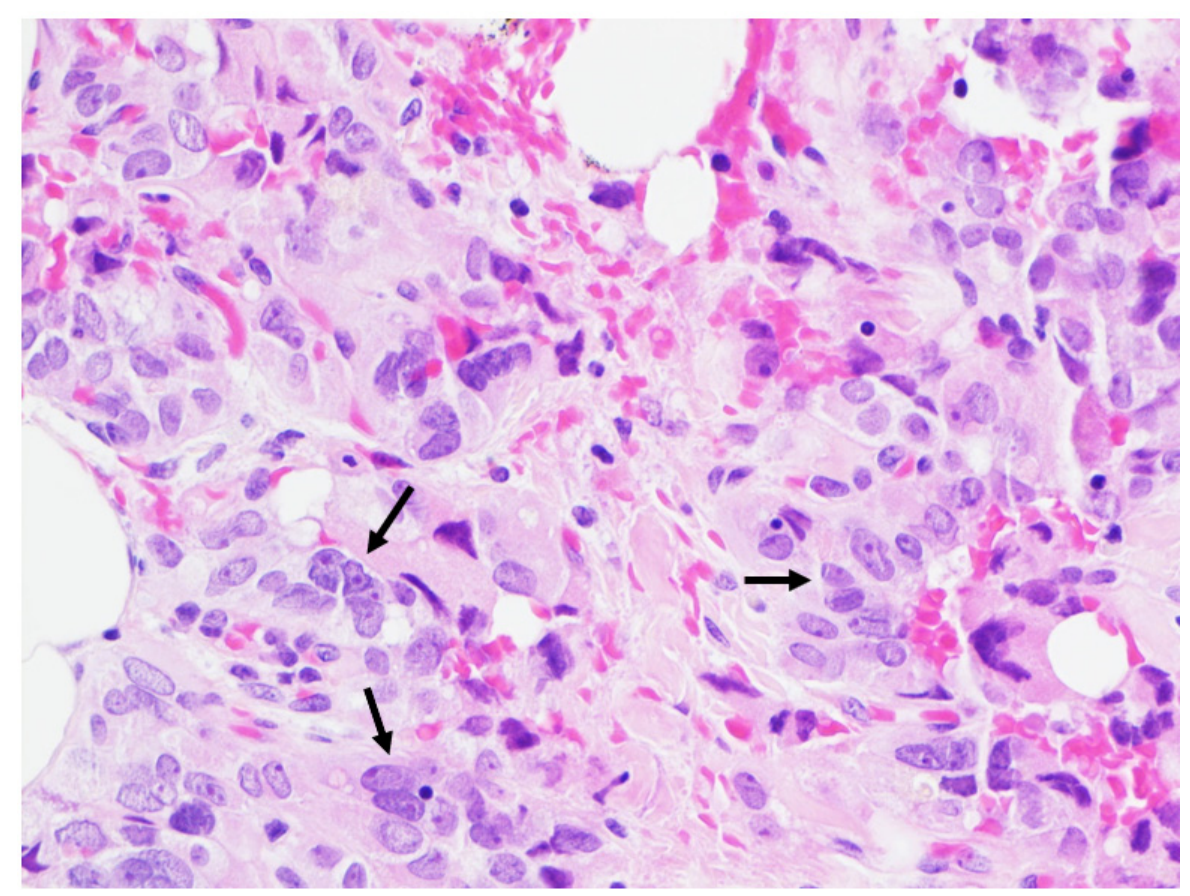

(E)

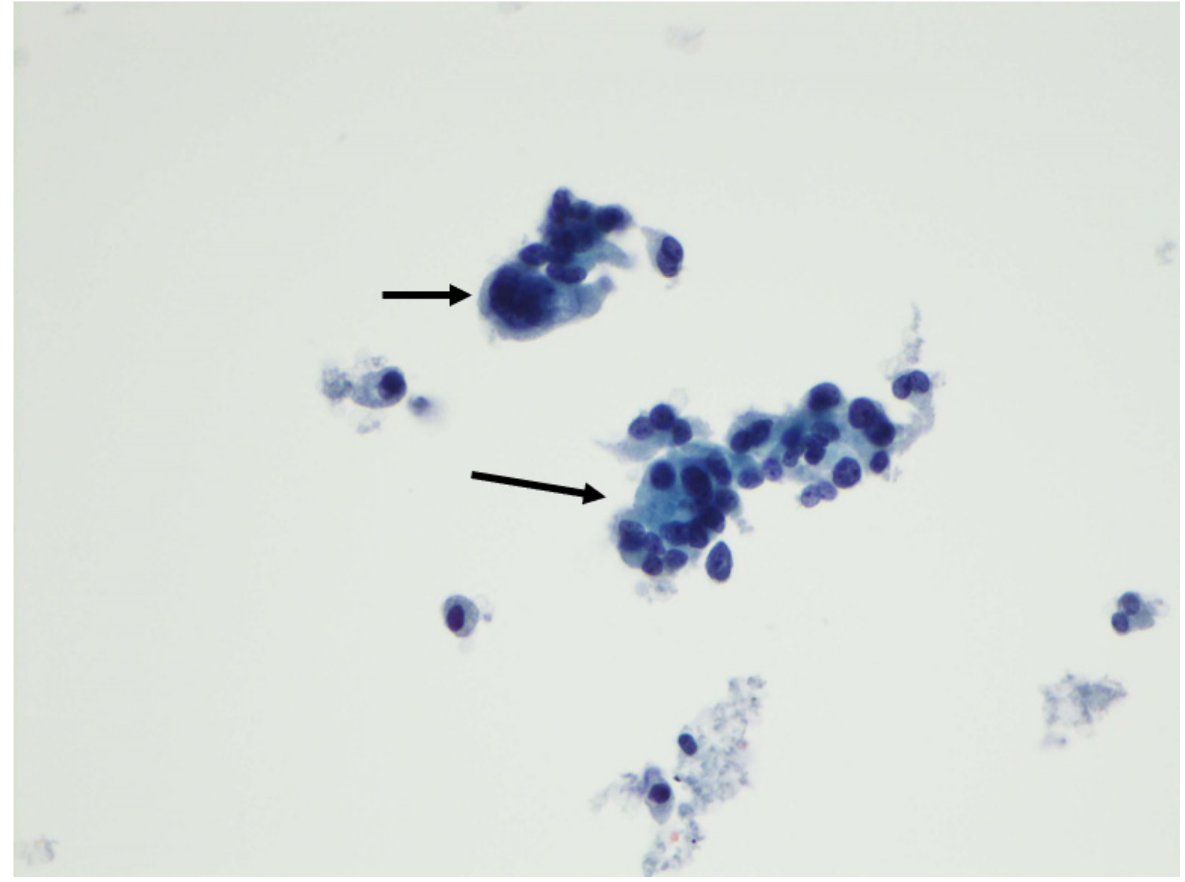

(F)

Figure 2. Cont. 


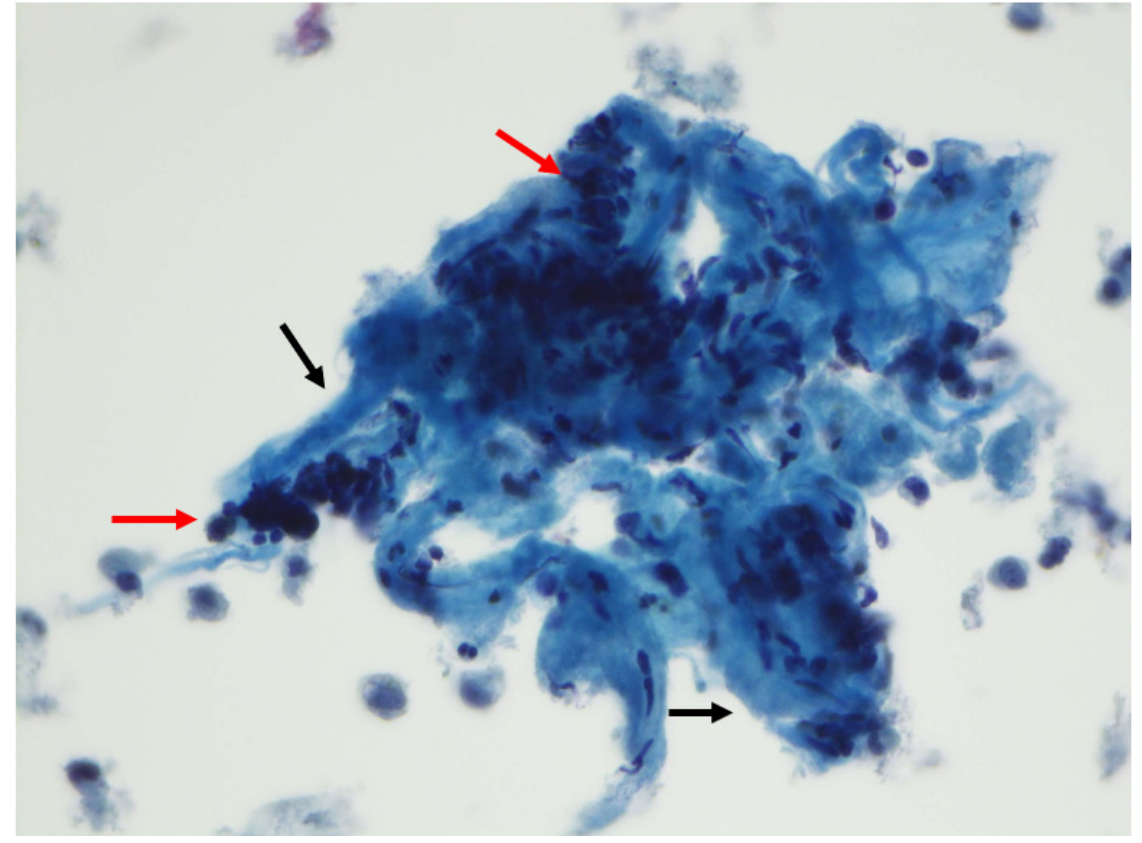

(G)

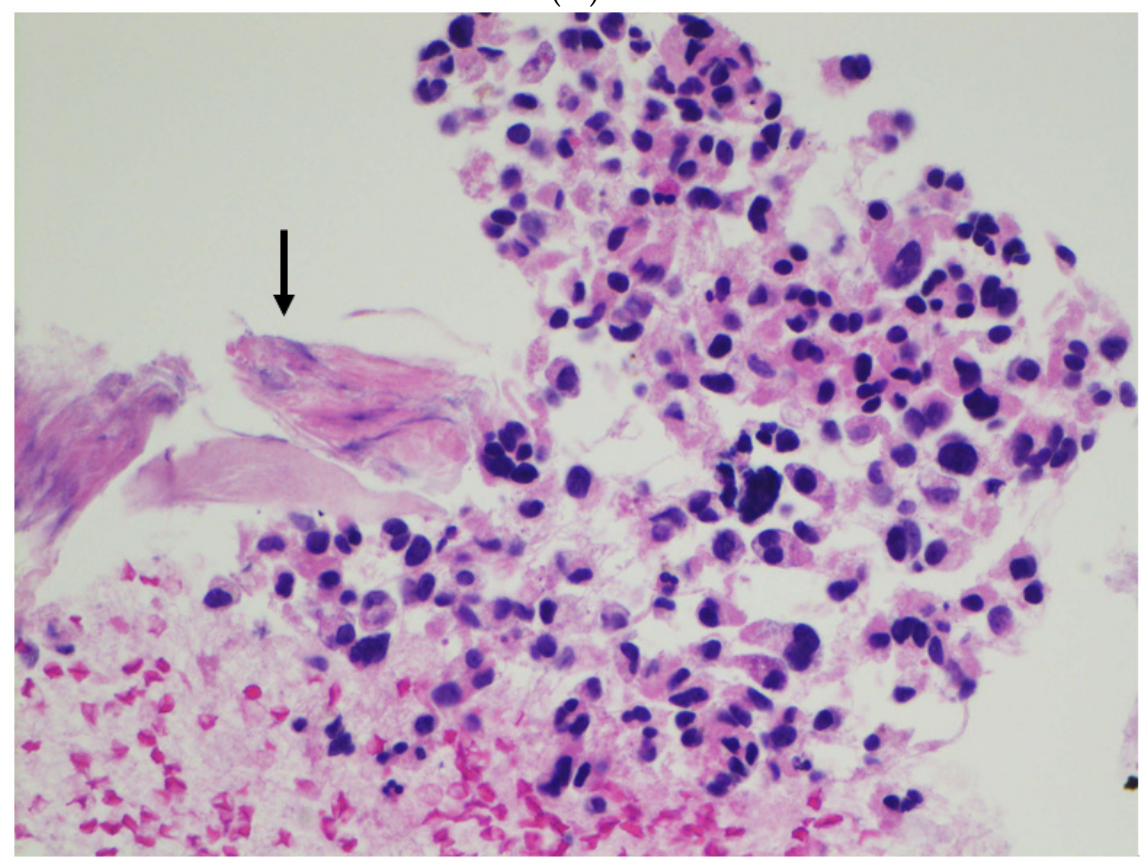

(H)

Figure 2. (A) Cholesterol crystals (Case \#7, EUS-FNA, Diff-Quik, original magnification $\times 100$ ). (B) Prominent clear cell changes (Case \#9, EUS-FNA, Diff-Quik, original magnification $\times 400$ ). (C) Prominent clear cell changes (Case \#9, EUS-FNA, cell block, H\&E, original magnification $\times 400$ ). (D) Monomorphic neoplastic cells in contrast to large pleomorphic atypical multinucleated giant cells (black arrows) with a vacuolated cytoplasm (Case \#12, EUS-FNA, Diff-Quik, original magnification $\times 400$ ). (E) Pleomorphic atypical multinucleated giant cells (black arrows) with nuclear irregularity (Case \#12, EUS-FNA, cell block, H\&E, original magnification $\times 400$ ). (F) Separate case showing atypical multinucleated giant cells (black arrows) (Case \#14, EUS-FNA, Papanicolaou, original magnification $\times 200$ ). (G) Hyalinized acellular stroma (black arrows) associated with atypical multinucleated giant cells (red arrows) (Case \#14, EUS-FNA, Papanicolaou, original magnification $\times 200)$. $($ H) Hyperchromatic atypical multinucleated giant cells and acellular hyaline and myxoid fibrovascular stroma (black arrow) (Case \#14, EUS-FNA, cell block, H\&E, original magnification $\times 200$ ). 
Rapid on-site evaluation (ROSE) was performed in ten cases. This included the evaluation of smears at the time of EUS-FNA in seven cases, and touch imprints at the time of CT-guided core biopsy in three cases. Lesional material was confirmed at the time of the procedure in all ten cases (Table 1). However, a definite diagnosis of SPN was rendered in only 1 of these 10 cases at ROSE. The differential diagnoses at ROSE included PanNETs and round cell tumors (two cases each). In the latter scenario, material was sent for flow cytometry; cells were positive for CD56 and CD10, and negative for CD45. One case was felt to have atypical cells with mucinous features. In reviewing the slides created at ROSE, we found that cercariform cells were seen in smears but not in touch imprints, leading us to hypothesize that this peculiar morphology may be the result of a stretching artefact caused by mechanical "strain" on the cell at the time of smearing.

Immunohistochemical stains were performed in 16 of the 17 cases with cytological material (Table 3), either for the confirmation of diagnosis or to resolve differential diagnoses. Where immunohistochemical stains were performed, $100 \%$ of cases were positive for nuclear $\beta$-catenin, CD10, $\alpha 1$-antitrypsin, CD56, cyclin-D1, progesterone receptor (PR), and vimentin. Interestingly, $46 \%$ of cases were positive for synaptophysin, but none were positive for chromogranin. Only 1 of the 11 cases was positive for pancytokeratin (CK AE1/AE3). Tumors showed a low Ki-67 proliferation index (not greater than 5\%). Im-munostaining for CD99 was only performed on Case \#15 and was negative.

Table 3. SPN: immunohistochemistry profile in cases with cytological material.

\begin{tabular}{llllllllllll}
\hline Case & $\beta$-Cat & CyD1 & PR & CD56 & SYN & CHR & CD10 & CK & VIM & AAT & Ki-67 \\
\hline 1 & + & NA & NA & + & Focal & NA & + & - & + & + & NA \\
2 & + & NA & NA & + & NA & NA & + & NA & + & + & NA \\
3 & NA & NA & NA & + & - & - & + & NA & NA & NA & NA \\
4 & + & NA & NA & + & Focal & - & + & - & + & + & NA \\
5 & + & NA & NA & + & Focal & - & + & - & + & + & NA \\
6 & + & NA & NA & NA & - & - & NA & NA & NA & + & NA \\
7 & NA & NA & NA & NA & NA & NA & NA & NA & NA & + & NA \\
8 & + & NA & NA & + & NA & NA & + & NA & NA & + & NA \\
9 & + & NA & NA & NA & Focal & - & + & + & NA & + & $<5 \%$ \\
10 & + & NA & + & + & - & - & + & - & NA & NA & $<1 \%$ \\
11 & + & + & + & NA & - & - & + & - & NA & NA & $<5 \%$ \\
12 & + & NA & NA & NA & - & - & NA & - & NA & NA & $<5 \%$ \\
13 & + & + & + & NA & Focal & - & NA & - & NA & NA & $5 \%$ \\
14 & + & + & + & NA & Focal & - & NA & - & NA & NA & $1 \%$ \\
15 & + & + & + & + & - & - & + & - & NA & + & NA \\
16 & + & + & + & NA & - & - & + & NA & + & NA & NA \\
17 & + & + & NA & NA & NA & NA & + & - & NA & NA & NA \\
\hline \multirow{2}{*}{ Total } & $15 / 15$ & $6 / 6$ & $6 / 6$ & $8 / 8$ & $6 / 13$ & $0 / 12$ & $12 / 12$ & $1 / 11$ & $5 / 5$ & $9 / 9$ \\
& $10 \%$ & $100 \%$ & $100 \%$ & $100 \%$ & $46 \%$ & $0 \%$ & $100 \%$ & $9 \%$ & $100 \%$ & $100 \%$ \\
\hline
\end{tabular}

Abbreviations: $\beta$-Cat, $\beta$-catenin; CyD1, cyclin-D1; PR, progesterone receptor; SYN, synaptophysin; $\mathrm{CHR}$, chromogranin; CK, cytokeratin AE1/AE3; VIM, vimentin; AAT, $\alpha 1$-antitrypsin; NA, not available.

The available clinical follow-ups ranged from 2 to 177 months, with a median of 69 months. Nineteen patients were alive and tested negative for recurrent or metastatic SPN. Three patients had no available clinical follow-up information.

\section{Discussions}

Pancreatic SPNs are rare, accounting for less than 3\% of pancreatic exocrine neoplasms [1-6]. We found only 22 cases in our database in a large tertiary care community practice over a 15-year period (to provide perspective, we have over 150 cases of EUS-FNA of pancreatic masses every year). These tumors are generally thought to affect young females. Analysis of the SEER database revealed that SPNs had a bimodal age-frequency distribution in females (early onset peak at $28 \mathrm{y}$ and late onset peak at $62 \mathrm{y}$ ), whereas male 
patients had a unimodal peak (64 years) [16]. While we did find a wide age range among our female patients, unlike the SEER database, all our male patients were young.

The symptoms of most patients with SPN are reported to be nonspecific, and some SPNs are incidentally discovered $[1,2,17]$. Most of our patients presented with abdominal pain or discomfort, and only in one case was the tumor incidentally discovered. The tumors in our cohort had a median dimension of $4.0 \mathrm{~cm}$ (mean: $4.7 \mathrm{~cm}$ ), which is smaller than the 6.6 to $8 \mathrm{~cm}$ size in other studies $[4,6,8,15]$, and comparable to a recent study [18]. Tumors are usually solitary and more frequently reported in the tail [1,2,4], similar to our cases.

Cytology has come to be a mainstay in the work-up and diagnosis of pancreatic tumors [7-11]. The cytological identification of SPN is important in order to prevent unnecessary aggressive treatments, including preoperative chemoradiation and radical surgery. With a sufficient sample, the diagnosis of SPN is usually straightforward since it has characteristic cytological features and IHC profiles $[7-15,18]$. The classical cytological features of SPN include pseudopapillary clusters with central fibrovascular cores surrounded by monomorphic neoplastic cells, with a small or moderate amount of cytoplasm [7-15]. In this study, pseudopapillary clusters with thin central capillaries were seen in all but one case. A varied amount of background extracellular myxoid hyalinized fibrovascular material was identified in all cases. Neoplastic cells had a mostly monomorphic plasmacytoid morphology with fine nuclear chromatin, without prominent nucleoli. The nuclear grooves or folds were better seen with Papanicolaou or H\&E stains [14].

The major differential diagnosis we encountered was pancreatic neuroendocrine tumor (PanNET). PanNET was mentioned as a preliminary diagnosis in a few cases at ROSE. In fact, Case \#3 was diagnosed as PanNET in the original final FNA report. The prominent pseudopapillary clusters with central capillaries, myxoid fibrovascular core/extracellular material, and cercariform cells offered clues for SPN. In contrast, PanNET neoplastic cells show salt and pepper nuclear chromatin, arranged in a single form or rosettes $[4,8,14]$.

Case \#1 showed abundant intracytoplasmic vacuoles on Diff-Quik-stained direct smears, leading to a ROSE diagnosis of "atypical cells with mucinous features." Given that this was a 65-year-old patient, the main consideration was of an adenocarcinoma. In our opinion, these intracytoplasmic vacuoles are intracellular eosinophilic hyaline globules that are immunoreactive for $\alpha 1$-antitrypsin. These findings are consistent with other studies [10,11]. One case showed clear cells resembling clear cell renal cell carcinoma [19,20], and the differential diagnosis was resolved by immunohistochemistry for PAX8: neoplastic cells were positive for $\beta$-catenin and negative for PAX-8.

As seen in our study, SPNs are typically immunoreactive for nuclear $\beta$-catenin, PR, cyclin-D1, CD10, $\alpha 1$-antitrypsin, and vimentin. The expression of pancytokeratin and synaptophysin is variable, while neoplastic cells are negative for chromogranin. Nuclear expression of $\beta$-catenin is specific to SPNs [21,22] due to somatic mutations in CTNNB1 exon three hotspots. PanNET, the most likely differential, would be positive for pancytokeratin, synaptophysin, and chromogranin. We propose a limited IHC panel including three nuclear stains (beta-catenin, PR, and cyclin-D1) and three cytoplasmic stains (CK AE1/AE3, synaptophysin, and chromogranin) to exclude NETs.

In this study, we identified three cases (Case \#12, 14, and 20) with atypical multinucleated giant cells. The findings were alarming, since malignant neoplasms with a worse prognosis entered the differential diagnosis, including PanNET with endocrine atypia, pancreatic carcinoma, and metastatic malignancy. As can be seen in Figure 3, the large atypical multinucleated neoplastic cells were immunoreactive for nuclear $\beta$-catenin, cyclin-D1, and PR, while they were negative for CK AE1 / AE3 and chromogranin, with a low proliferation index, confirming the diagnosis of SPN. Similar giant cells have recently been described in a few reports [23-25]. Interestingly, all of our cases with atypical cells occurred in relatively older patients, leading to the consideration of pancreatic carcinoma. It is therefore important to remember that SPNs can occur in older individuals and can present with degenerative atypia. Unlike pancreatic adenocarcinomas and NETs, SPNs are low-grade tumors with an excellent prognosis, as in our cohort. 


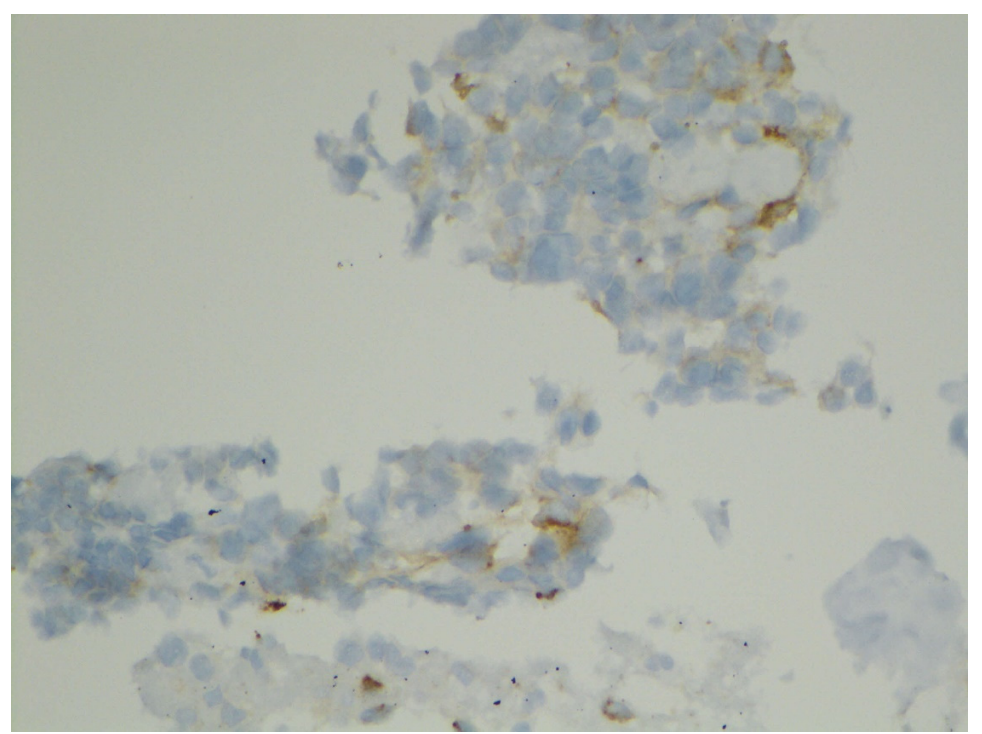

(A)

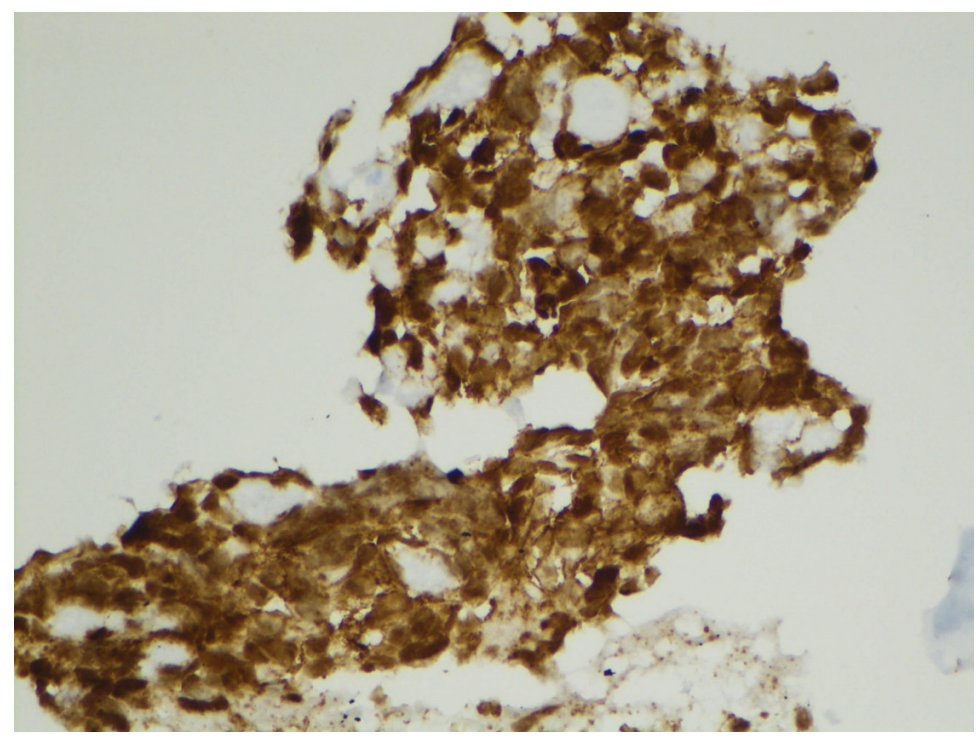

(B)

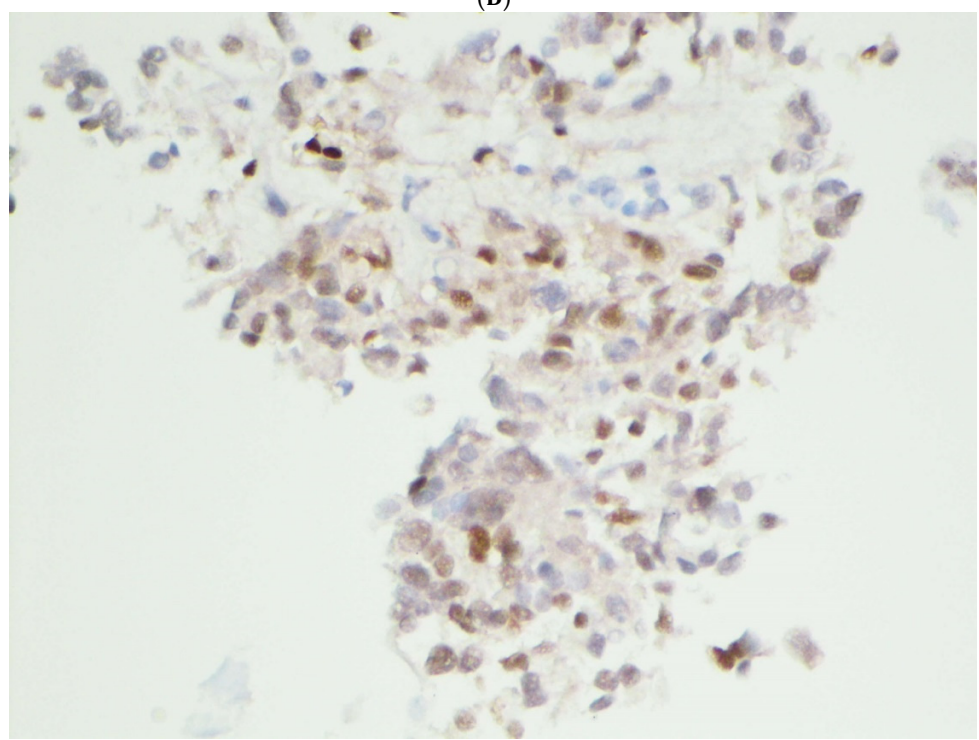

(C)

Figure 3. Cont. 


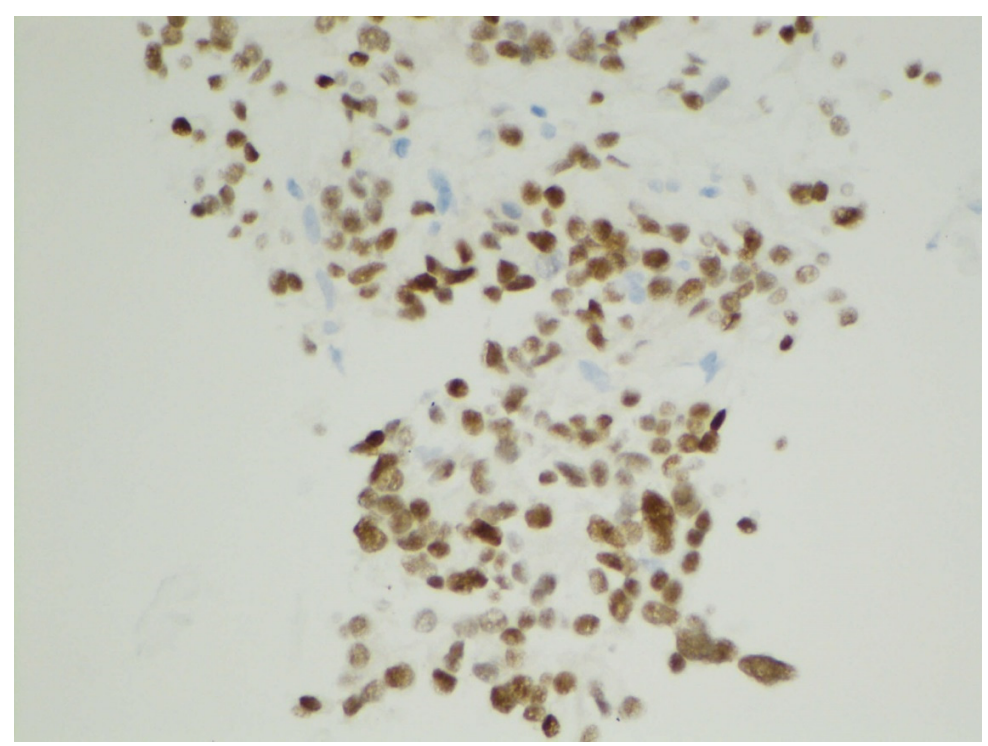

(D)

Figure 3. (A) Weak immunostaining for synaptophysin (Case \#14, cell block, original magnification $\times 400$ ). (B) Strong nuclear and cytoplasmic immunostaining for $\beta$-catenin (Case \#14, cell block, original magnification $\times 400$ ). (C) Nuclear immunostaining for cyclin-D1 (Case \#14, cell block, original magnification $\times 400$ ). (D) Nuclear immunostaining for progesterone receptor (Case \#14, cell block, original magnification $\times 400)$.

\section{Conclusions}

We have presented our experience with cytological diagnoses of SPN in a wellcharacterized cohort of 22 patients with histological correlation and follow-up data. These tumors occur over a wide range and show varied cytological features. SPNs can be confidently diagnosed even on limited cytologic material. Recognizing associated degenerative changes is crucial in avoiding a misdiagnosis. A strong suspicion irrespective of age and gender, attention to cytological details, and the application of a limited IHC panel can be helpful in establishing a definitive diagnosis, and patient management.

Author Contributions: B.G.W.: conceptualization, data curation, investigation, methodology, formal analysis, picture taking, writing (original draft, review and editing, final draft). H.M.: writing (review and editing). Z.Q.W.: data curation, table making, writing (review and editing). W.L.: writing (review and editing). All authors have read and agreed to the published version of the manuscript.

Funding: This research received no external funding. The APC was funded by personal fund.

Institutional Review Board Statement: Per INOVA, this project did not constitute human subject research and did not require IRB review. An institutional IRB waiver was obtained for this retrospective study using records and material obtained for routine clinical care; this study was not regarded as a human subject research study by the Inova Health System IRB.

Informed Consent Statement: Patient consent was waived due to no interaction with human subject and no involvement of identifiable private information.

Data Availability Statement: This study did not report any data.

Conflicts of Interest: The authors declare no conflict of interest.

\section{References}

1. Klöppel, G.; Basturk, O.; Klimstra, D.S.; Lam, A.K.; Notohara, K. Solid pseudopapillary neoplasm of the pancreas. In WHO Classification of Tumors: Digestive System Tumours, 5th ed.; WHO Classification of Tumours Editorial Board; IARC Press: Lyon, France, 2019; Volume 1, pp. 340-342.

2. Hruban, R.H.; Pitman, M.B.; Klimstra, D.S. Solid-pseudopapillary neoplasms. In Atlas of Tumor Pathology, Series 4: Tumors of the Pancreas; Hruban, R.H., Pitman, M.B., Klimstra, D.S., Eds.; Armed Forces Institute of Pathology: Washington, DC, USA, 2007; pp. 231-250. 
3. Klimstra, D.S.; Wenig, B.M.; Heffess, C.S. Solid-pseudopapillary tumor of the pancreas: A typically cystic carcinoma of low malignant potential. Semin. Diagn. Pathol. 2000, 17, 66-80. [PubMed]

4. Dinarvand, P.; Lai, J. Solid pseudopapillary neoplasm of the pancreas: A rare entity with unique features. Arch. Pathol. Lab. Med. 2017, 141, 990-995. [CrossRef]

5. La Rosa, S.; Bongiovanni, M. Pancreatic solid pseudopapillary neoplasm: Key pathologic and genetic features. Arch. Pathol. Lab. Med. 2020, 144, 829-837. [CrossRef]

6. $\quad$ Estrella, J.S.; Li, L.; Rashid, A.; Wang, H.; Katz, M.H.; Fleming, J.B.; Abbruzzese, J.L.; Wang, H. Solid pseudopapillary neoplasm of the pancreas: Clinicopathologic and survival analyses of 64 cases from a single institution. Am. J. Surg. Pathol. 2014, 38, 147-157. [CrossRef]

7. Pelosi, G.; Iannucci, A.; Zamboni, G.; Bresaola, E.; Iacono, C.; Serio, G. Solid and cystic papillary neoplasm of the pancreas: A clinico-cytopathologic and immunocytochemical study of five new cases diagnosed by fine-needle aspiration cytology and a review of the literature. Diagn. Cytopathol. 1995, 13, 233-246. [CrossRef] [PubMed]

8. Pettinato, G.; Di Vizio, D.; Manivel, J.C.; Pambuccian, S.E.; Somma, P.; Insabato, L. Solid-pseudopapillary tumor of the pancreas: A neoplasm with distinct and highly characteristic cytological features. Diagn. Cytopathol. 2002, 27, 325-334. [CrossRef]

9. Bardales, R.H.; Centeno, B.; Mallery, J.S.; Lai, R.; Pochapin, M.; Guiter, G.; Stanley, M.W. Endoscopic ultrasound-guided fineneedle aspiration cytology diagnosis of solid-pseudopapillary tumor of the pancreas: A rare neoplasm of elusive origin but characteristic cytomorphologic features. Am. J. Clin. Pathol. 2004, 121, 654-662. [CrossRef]

10. Jhala, N.; Siegal, G.P.; Jhala, D. Large, clear cytoplasmic vacuolation: An under-recognized cytologic clue to distinguish solid pseudopapillary neoplasms of the pancreas from pancreatic endocrine neoplasms on fine-needle aspiration. Cancer 2008, 114, 249-254. [CrossRef] [PubMed]

11. Samad, A.; Shah, A.A.; Stelow, E.B.; Alsharif, M.; Cameron, S.E.H.; Pambuccian, S.E. Cercariform cells: Another cytologic feature distinguishing solid pseudopapillary neoplasms from pancreatic endocrine neoplasms and acinar cell carcinomas in endoscopic ultrasound-guided fine-needle aspirates. Cancer Cytopathol. 2012, 121, 298-310. [CrossRef]

12. Burford, H.; Baloch, Z.; Liu, X.; Jhala, D.; Siegal, G.P.; Jhala, N. E-cadherin/ $\beta$-catenin and CD10: A limited immunohistochemical panel to distinguish pancreatic endocrine neoplasm from solid pseudopapillary neoplasm of the pancreas on endoscopic ultrasound-guided fine-needle aspirates of the pancreas. Am. J. Clin. Pathol. 2009, 132, 831-839. [CrossRef]

13. Bal, M.M.; Deodhar, K.; Shrikhande, S.; Shukla, P.; Arya, S.; Ramadwar, M. Solid pseudopapillary tumor of the pancreas: "Experiences" and "Lessons" at a tertiary-care oncology center. Diagn. Cytopathol. 2012, 41, 599-606. [CrossRef]

14. Misra, S.; Saran, R.K.; Dm, S.S.; Barman, S.; Dahale, A. Utility of cytomorphology in distinguishing solid pseudopapillary neoplasm of pancreas from pancreatic neuroendocrine tumor with emphasis on nuclear folds and nuclear grooves. Diagn. Cytopathol. 2019, 47, 531-540. [CrossRef] [PubMed]

15. Singh, P.; Kumar, P.; Rohilla, M.; Gupta, P.; Gupta, N.; Dey, P.; Srinivasan, R.; Rajwanshi, A.; Nada, R. Fine needle aspiration cytology with the aid of immunocytochemistry on cell-block confirms the diagnosis of solid pseudopapillary neoplasm of the pancreas. Cytopathology 2020, 32, 57-64. [CrossRef]

16. Wu, J.; Mao, Y.; Jiang, Y.; Song, Y.; Yu, P.; Sun, S.; Li, S. Sex differences in solid pseudopapillary neoplasm of the pancreas: A population-based study. Cancer Med. 2020, 9, 6030-6041. [CrossRef] [PubMed]

17. Lanke, G.; Ali, F.S.; Lee, J.H. Clinical update on the management of pseudopapillary tumor of pancreas. World J. Gastrointest. Endosc. 2018, 10, 145-155. [CrossRef]

18. Ardengh, J.C.; Lopes, C.V.; Venco, F.E.; Machado, M.A. Diagnosis of pancreatic solid pseudopapillary neoplasms using cell-blocks and immunohistochemical evaluation of endoscopic ultrasound-guided fine needle aspiration biopsy specimens. Cytopathology 2020, 32, 50-56. [CrossRef]

19. Albores-Saavedra, J.; Simpson, K.W.; Bilello, S.J. The clear cell variant of solid pseudopapillary tumor of the pancreas: A previously unrecognized pancreatic neoplasm. Am. J. Surg. Pathol. 2006, 30, 1237-1242. [CrossRef]

20. Zhao, P.; Debrito, P.; Ozdemirli, M.; Sidawy, M.K. Solid-pseudopapillary neoplasm of the pancreas: Awareness of unusual clinical presentations and morphology of the clear cell variant can prevent diagnostic errors. Diagn. Cytopathol. 2013, 41, 889-895. [CrossRef] [PubMed]

21. Tanaka, Y.; Kato, K.; Notohara, K.; Hojo, H.; Ijiri, R.; Miyake, T.; Nagahara, N.; Sasaki, F.; Kitagawa, N.; Nakatani, Y.; et al. Frequent beta-catenin mutation and cytoplasmic/nuclear accumulation in pancreatic solid-pseudopapillary neoplasm. Cancer Res. 2001, 61, 8401-8404.

22. Kim, M.-J.; Jang, S.-J.; Yu, E. Loss of E-cadherin and cytoplasmic-nuclear expression of $\beta$-catenin are the most useful immunoprofiles in the diagnosis of solid-pseudopapillary neoplasm of the pancreas. Hum. Pathol. 2008, 39, 251-258. [CrossRef]

23. Li, L.; Othman, M.; Rashid, A.; Wang, H.; Li, Z.; Katz, M.H.; Lee, J.E.; Pisters, P.W.; Abbruzzese, J.L.; Fleming, J.B.; et al. Solid pseudopapillary neoplasm of the pancreas with prominent atypical multinucleated giant tumour cells. Histopathology 2012, 62, 465-471. [CrossRef] [PubMed]

24. Kim, S.A.; Kim, M.-S.; Kim, S.C.; Choi, J.; Yu, E.; Hong, S.-M. Pleomorphic solid pseudopapillary neoplasm of the pancreas: Degenerative change rather than high-grade malignant potential. Hum. Pathol. 2014, 45, 166-174. [CrossRef] [PubMed]

25. Policarpio-Nicolas, M.L.C.; McHugh, K.E.; Sae-Ow, W.; Brainard, J.A. Pleomorphic and atypical multinucleated giant cells in solid pseudopapillary neoplasm of pancreas: A diagnostic pitfall in cytology and a review of the literature. Diagn. Cytopathol. 2018, 47, 488-493. [CrossRef] [PubMed] 